\title{
Learning Styles of Australian Aviation Students: An Assessment of the Impact of Culture
}

\author{
Yi Gao, Kai Tai Stephen Au, Hyuk Joo Kwon, and Eu Wing Leong \\ Swinburne University of Technology
}

\begin{abstract}
Australia has a rich history in aviation and has the tradition of being a pilot training provider for many decades. Students from all over the world are being attracted to Australia every year with the ambition of becoming a commercial pilot. An understanding of the impact of national cultures on the learning styles of student pilots from different culture backgrounds will be beneficial to the overall quality of pilot education in Australia. In this study, students enrolled in the aviation (pilot) program of Swinburne University of Technology were surveyed using Kolb's Learning Style Inventory, and subsequent analysis was performed to the survey data. It was found that a predominant percentage of aviation students were adopting converging and assimilating styles. When comparing findings of this project with previous studies using samples from China and the United States, Australian students' preference of abstract conceptualization was found to be quite similar to that of American students and different from Chinese students, which is an indication of the impact of national culture on learning style preference. This newfound knowledge of Australian aviation students will help raise the understanding how aviation students of different cultural backgrounds learn piloting skills and provide insightful information for flight training academies and researchers.
\end{abstract}

\section{Introduction}

Australia is one of the leading countries to provide quality flight training to future aspiring pilots around the world. Cathay Pacific Airways, Qantas Airways, Jetstar, Vietnam Airlines, and Singapore Airlines are examples of companies that have agreements with various Australian flight-training providers. With this agreements, responsibility is entrusted onto these training providers for a professional quality of training that will ensure a high level of safety, efficiency and professionalism will be attained by these aspiring pilots.

Understanding how these students acquire both ground theory and practical piloting skills will help flight training providers adjust their training curriculum and more importantly, the instruction style, to cater to the need of students to improve the training outcome. This in turn will be beneficial to flight schools as they recruit international students. Students themselves will also benefit from knowing their own learning style, as they will be able to develop a more efficient way of learning with the assistance of learning style theory. 
The study of learning styles has been a topic of interest, and several methods have been employed to determine preferred learning styles. For example, McCall, Klein, Piterman and Lam (2005) conducted a study on Hong Kong general practitioners by employing the Honey and Mumford's Model of Learning Style and found the predominant learning style to be reflective. Mitsis and Foley (2004) found that teacherdriven learning style characteristics are associated with countries that have high masculinity, high Confucian, high uncertainty avoidance and high collectivism ratings. More specifically in aviation, Kanske (2001) conducted a survey on United States Air Force pilots using the Kolb's Learning Style Inventory (KLSI) and found that the majority of students' learning styles to be of converging. Recently, Fanjoy and Gao (2011) studied the learning style of Chinese students enrolled in the aviation program of the Civil Aviation University of China and found a shift of learning style preference from being assimilating and converging in lower year groups to diverging and assimilating when they progressed in the aviation program. The difference of learning style preference between American students and Chinese students suggests a possible effect of national culture on learning styles.

According to Joy and Kolb (2009), culture does have an influence on an individual's learning style preference, though the influence is only marginal. By examining the influence of individual culture dimensions on learning style preference, Joy and Kolb concluded that students from culture backgrounds that are high in in-group collectivism, institutional collectivism, uncertainty avoidance, future orientation and gender egalitarianism are more likely to adopt an abstract learning style, whereas individuals from countries that are high in in-group collectivism, uncertainty avoidance and assertiveness may have a more reflective learning style.

The findings of several studies concurred with Joy and Kolb that cultural difference correlates with learning style preference (Berry, 1996; Claxton, 1990; Creason, 1992; Henderson \& Washington, 1975; Lee \& Carrasquillo, 2006; Kennedy, 2002; Nelson, 1995). Nelson (1995) and Ramirez III (1989) advocated that socialization and cultural background shape children's learning styles through their early experiences. Singleton (in Finkelstein, Imamura \& Tobin, 1991) further acknowledged that learning style is developed at a very early age through sharing culturally based patterns of behavior. Not only that, the cultural pattern also guides the educational curriculum.

In spite of culture being in some way related to learning style, it does not mean that a group of students from the same cultural background share similar characteristics in learning. Many other factors may affect the preference of one's learning style, such as gender, age, religion, family structure, native language, work history, socioeconomic class, area of specialization, etc. (Kolb \& Kolb, 2005). Dunn (1997, p. 74-75) asserted, "there is no single or dual learning style for the members of any culture, national, racial, or religious group," and diversity exists not just between cultures, but also within a single culture.

Hofstede (1996) defined five cultural dimensions, which are Power Distance Index (PDI), Individualism (IDV), Masculinity (MAS), Uncertainty Avoidance Index (UAI) and Long-Term Orientation (LTO) to describe and compare national cultures. There are 
other studies regarding national culture in the past, such as value orientation framework (Kluckhohn \& Strodtdbeck, 1961), Trompenaars' Relationship Dimensions (Trompenaars \& Hampden-Turner, 1997), Hall's Cultural Factors (Hall, 1966). However, none of them has as wide or diverse coverage of the population of countries as Hofstede's study. See Figure 1 for a comparison of national culture among Australia, China, and the United States using Hofstede's culture dimensions. It can be noted in the figure the similarity between American and Australian culture and the distinction between these two cultures and the Chinese culture.

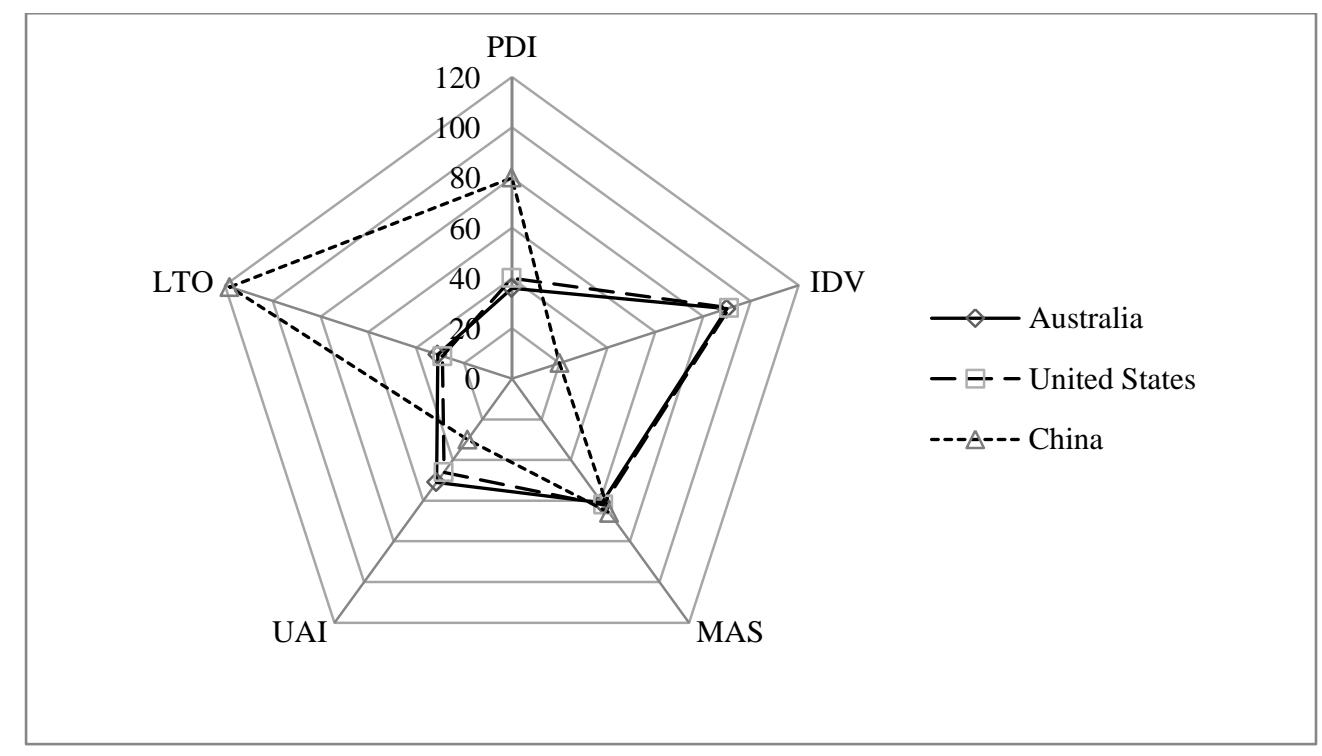

Figure 1. A comparison of national cultural dimensions (Hofstede, 1996).

At the moment, studies regarding learning and teaching of aviation students in Australia are limited. Therefore this study mainly aims to investigate the learning style preference of students enrolled in the aviation program of Swinburne University of Technology using Kolb's Learning Style Inventory. Results of the investigation will be used to compare prior studies in nations of other culture background to assess the impact of culture on learning style preference.

\section{Method}

The subjects of this study were students enrolled in the Bachelor of Aviation course or Bachelor of Aviation/Commerce double degree course at Swinburne University of Technology (SUT) in 2011. For students undertaking the aviation course at SUT, flight training was conducted by what was then Oxford Aviation Academy, now known as CAE Oxford Aviation Academy (COAA). These students, ranging from Year One to Year Four in their course of study, were at different stages of their flight training, including Private Pilot's Licence (PPL), Commercial Pilot's Licence (CPL) and the theory part of Civil Aviation Safety Authority (CASA) Air Transport Pilot Licence (ATPL). In 2011, the total number of students enrolled in the aviation course of SUT was 223, out of which 76 students were in year one, 70 were in year two, 74 were in year three, and three were in Year four. The age of students ranged from 18 to 28. 
This project used the method of survey to investigate learning styles of students being trained at SUT/COAA. The survey instrument consisted of demographic questions and the Kolb Learning Style Inventory (KLSI), which was authorized by the Hay Group to be used in this study. The demographic part asked questions to identify students' age, gender, country of residence in the past 10 years, flight experiences in hours, licence qualification and current year of study.

KLSI is a popular instrument widely adopted to analyse learning styles in various fields, and has been frequently used by researchers in previous similar studies (Fanjoy \& Gao, 2011; Kanske, 2001; Kanske \& Brewer, 2001). KLSI is helpful in providing a framework to discuss the learning process where students could better their learning experiences. At the same time, Kolb (1976) himself and other researchers (Loo, 1997; Ruble \& Stout, 1992) found that scores of test and re-test using earlier versions of KLSI lacked consistence. Kolb then had made changes to KLSI to improve the test-retest reliability, the improvement of which was confirmed by several studies (Romero, Tepper \& Tetrault, 1992; Veres III, Sims \& Locklear, 1991). By using the same survey instrument, a constructive comparison can be made between this study and results from previous studies to assess the impact of national culture.

The Human Research Ethics Committee of Swinburne University of Technology approved the project, allowing the survey to be carried out in COAA. Hard copies of the survey questionnaire were distributed to students attending ground theory lectures at COAA, which is located in Moorabbin Airport, Victoria, Australia. Before taking the survey, participants were informed in advance that the completion of survey was completely voluntary and that they would remain anonymous throughout and after the study. Students were then asked to fill the questionnaire while researchers were present, and to return filled questionnaires back to researchers after completion.

Data collected from the student sample were analysed with a rubric obtained from the Hay Group to yield a grid score on the Abstract Conceptualisation/Concrete Experience (AC-CE) axis and Active Experimentation/Reflective Observation (AE-RO) axis respectively. The coordination of the grid scores identified learning style of individuals as accommodating, diverging, assimilating, or converging. See Figure 2 for the LearningStyle Type Grid.

Besides the determination of learning styles of the student sample, this study also compared student pilots of SUT, representing Australian aviation students, with student pilots of other nations to assess the impact culture in shaping students' cognitive styles. Therefore, statistical analysis was used to compare learning styles of aviation student samples from Australia, China, and the USA. 


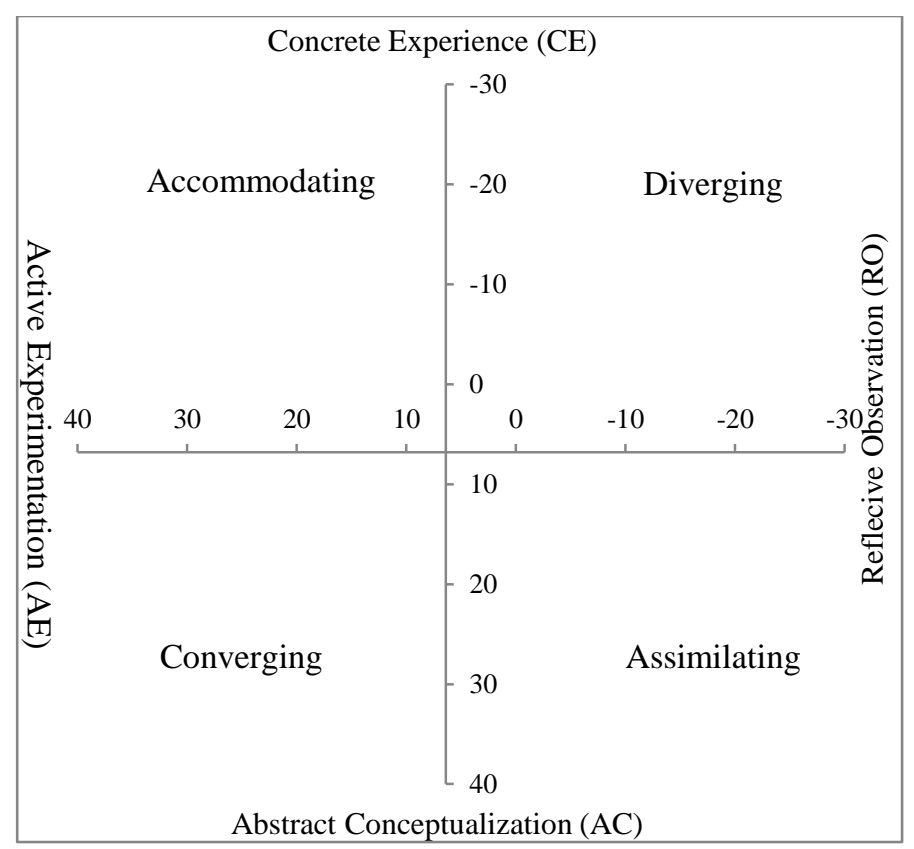

Figure 2. Kolb's Learning-Style type grid (Kolb \& Kolb, 2005).

In this study, it was assumed that students in the aviation course of SUT/COAA who had resided in Australia for longer than ten years at the time of the survey were good representatives of Australian student pilots body and the Australian culture so that a comparison with students from other nations could be made to assess the impact of culture. All survey participants were assumed to answer survey questions truthfully according to their learning habits therefore the result is an accurate indication of their learning style preference.

\section{Results}

In total 91 survey questionnaires were distributed and three of them were not retrieved, giving a response rate of 96.7 per cent. Seven of the collected questionnaires were inappropriately answered, and consequently, were not included in the following analysis. The number of valid responses covers $36.3 \%$ of all the aviation students enrolled in the aviation program as of Semester 2, 2011.

The 81 valid responses consisted of 29 Year one students (36\%), 26 Year two students (32\%), and 26 Year three students (32\%). In Australian Tertiary education system, an undergraduate program usually consists of three years of full time study. Therefore, Year four, which only had three students enrolled at the time of the survey, was not represented by the sample of this study. Among these 81 subjects, four of them were international students (4.9\%), and the rest of students had resided in Australia for longer than ten years. The participation of the survey once again confirmed that aviation is a male-dominant industry with 74 out of 81 subjects being male. 
Using the KLSI rubric provided by the Hay group, the scores of AC-CE and AE-RO were calculated for each filled questionnaire, and the corresponding learning style of each student was determined using the LSI type grid. In the sample of 81 students, 30 were found to adopt converging style (37.0\%), 27 were assimilating (33.3\%), 17 were diverging $(21.0 \%)$, and 7 were accommodating (8.7\%). Figure 3 depicts the distribution of learning styles of the respondents.

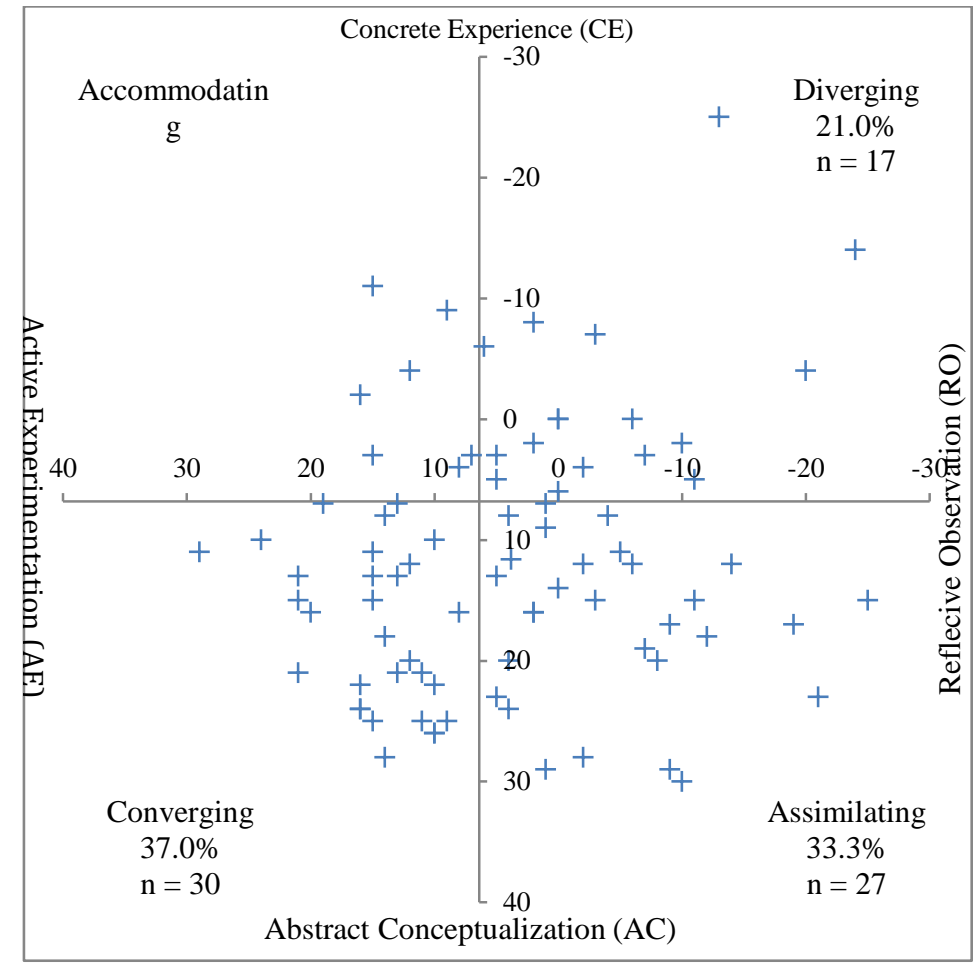

Figure 3. Distribution of students' learning styles on KLSI type grid.

The sample means for AC-CE and AE-RO are 11.63 and 3.83, and the $95 \%$ confidence internals for both means are $(9.15,14.11)$ and $(1.21,6.44)$ respectively. The KLSI rubric uses the $\mathrm{AC}-\mathrm{CE}=6.8$ and $\mathrm{AE}-\mathrm{RO}=6.4$ as reference values to determine learning style preference. It can be noted that the sample demonstrated a statistically significant preference of Abstract Conceptualisation (AC) over Concrete Experience (CE), though no significance could be found on Active Experimentation (AE) over Reflective Observation (RO). The preference of Abstract Conceptualisation over Concrete Experience can also be viewed from Figure 3, where a majority of respondents, or 57 out of $81(70.4 \%)$ to be exact, were found to have a learning style of either Converging or Assimilating. And the rest 24 (29.6\%) respondents were categorized as Accommodating or Diverging.

A breakdown of learning styles preferences by students of different year groups can be seen in Table 1. Because the sample size for each year group was relatively small, this study did not compare learning styles of different year groups. 
Table 1. Learning Style Preference by Year Group

\begin{tabular}{llll}
\hline & \multicolumn{1}{c}{ Year 1 } & \multicolumn{1}{c}{ Year 2 } & \multicolumn{1}{c}{ Year 3 } \\
\hline Converging & $13(44.8 \%)$ & $10(38.5 \%)$ & $7(26.9 \%)$ \\
Diverging & $2(6.9 \%)$ & $9(34.6 \%)$ & $6(23.1 \%)$ \\
Assimilating & $10(34.5 \%)$ & $7(26.9 \%)$ & $10(38.5 \%)$ \\
Accommodating & $4(13.8 \%)$ & $0(0 \%)$ & $3(11.5 \%)$ \\
\hline
\end{tabular}

In addition to exploring the learning style preference of the Australian sample, another objective of this study was to compare the current sample from Australia with prior studies in China (Fanjoy \& Gao, 2011) and USA (Kanske, 2001). Table 2 provides statistics of students' learning style preference of three different samples. In terms of AC$\mathrm{CE}$, similar to the Australian sample, the American sample demonstrated a skewed preference toward Abstract Conceptualization, though the preference is marginal. By contrast, the Chinese sample displays a more balanced preference between Abstract Conceptualisation and Concrete Experience.

In terms of AE-RO, the Chinese sample shows a significant preference of Reflective Observation over Active Experimentation. The Australian sample also displays a marginal preference towards Active Experimentation. The American sample, on the other hand, is more balanced and does not show noticeable preference to Reflective Observation or Active Experimentation.

Table 2. Comparison of learning style preference among different samples

\begin{tabular}{lcrccrrr}
\hline & \multirow{2}{*}{ Sample Size } & \multicolumn{3}{c}{ AC-CE $($ reference=6.8) } & \multicolumn{3}{c}{ AE-RO (reference=6.4) } \\
\cline { 3 - 8 } & & Mean & S.D. & 95\% C.I. & Mean & \multicolumn{1}{c}{ S.D. } & 95\% C.I. \\
\hline Australia & 81 & 11.63 & 11.22 & $(9.15,14.11)$ & 3.83 & 11.83 & $(1.21,6.44)$ \\
China & 293 & 6.70 & 10.30 & $(5.52,7.89)$ & 3.12 & 9.02 & $(2.08,4.16)$ \\
U.S.A. & 233 & 8.39 & 14.86 & $(6.78,10.00)$ & 5.93 & 12.41 & $(4.59,7.27)$ \\
\hline
\end{tabular}

\section{Conclusion}

The study found that the predominant learning styles of the SUT/COAA aviation students were converging and assimilating, which together accounted for $70.3 \%$ of the sample. A major of the students preferred Abstract Conceptualization over Concrete Experience when they learn. The preference of Abstract Conceptualization and the dominance of converging and assimilating among the Australian sample are similar to previous studies completed by Kanske (2001) and Kanske, Brewster and Fanjoy (2003) on American aviation students. In terms of modes of transforming experience (AE vs. $\mathrm{RO}$ ), the Australian sample demonstrated a more balanced preference, compared with Chinese students who preferred Reflective Observation over Active Experimentation.

Results of this study suggest the possible impact of national culture on the preference of learning styles. Australian and American aviation students' preference for Abstract Conceptualization and Chinese students' preference for Reflective Observation can be explained by Yamazaki's (2005) meta-analysis of learning style studies on samples from different cultural backgrounds. Yamazaki (2005) found that people from cultures of low- 
context, M-type organization, independent-self, and field-independent, typical characteristics of western countries such as the U.S.A and Australia, preferred Abstract Conceptualization, and people from cultures of strong uncertainty avoidance, interdependent-self, and guilt culture, such as Japan and China, would prefer Reflective Observation.

The preference of Abstract Conceptualization means that pilot students are willing to use systematic planning and theory to solve problems. Although pilot skills, in the traditional sense, mostly means the operation of aircraft, which comes from repetitive practice, findings of the present study indicates that most SUT students understand the importance of theory, such as aerodynamics, and prefer to use theoretical learning to guide their practical flight training. Therefore, while most flight schools deploy a larger percent of their resource on flight training, they should also value ground theory instruction, pre-flight planning and post-flight debriefing to reinforce training outcomes.

While the study by Joy and Kolb (2009) found that culture had a significant impact on the preference between Abstract Conceptualization and Concrete Experience and a marginal impact on the preference between Active Experimentation and Reflective Observation, the impact of culture was found to be lower than that of area of specialization. Aviation, as a highly specialized area, usually requires trainees with certain psychomotor skills and mandates rigorous flight-training syllabus. If mean values of AC-CE and AE-RO of samples are used to determine the representative learning style of a particular group, then the representative learning style of aviation students from Australia, China and the U.S.A will all be assimilating. Compared with samples from diverse areas of specialization (Yamazaki, 2005), learning style preference of aviation students from different cultures showed a certain level of similarity.

It has to be noted that the sample size in this study is not large enough to conduct a statistical analysis to compare learning styles of students from different year groups. Therefore, we were unable to test if the study in the aviation program has any effect on the evolution of students' learning styles. Students in the sample of this study were extracted from a single aviation program. And due to the possible variation among students and the training syllabi of different states, the sample of this study may not well represent the aviation students of Australia as a whole.

Future studies could include more aviation programs all across Australia. Besides the tertiary education sector, students learning how to fly in aviation clubs around Australia should be also included, which would broaden the scope of the study and provide a more representative result. With an expanded scope of study, the impact of national culture on learning styles could also be more accurately assessed. 


\section{References}

Berry, J. W. (1966). Temne and Eskimo perceptual skills. International Journal of Psychology, 1(3), 207-229.

Claxton, C. (1990). Learning styles, minority students, and effective education. Journal of Development Education, 14(1), 6-8.

Creason, P. (1992). Changing demographics and the importance of culture in student learning style. Retrieved from Education Resources Information Centre: http://www.eric.ed.gov/PDFS/ED361270.pdf

Dunn, R. (1997). The goals and track record of multicultrual education. Educational Leadership, 54(7), 74-77.

Fanjoy, R., \& Gao, Y. (2011). Learning Styles of Chinese aviation students. International Journal of Applied Aviation Studies, 11(1), 57-65.

Hall, E. (1966). The Hidden Dimension. New York: Doubleday.

Henderson, D., \& Washington, A. (1975). Cultural difference and the education of black children: An alternative model for program development. Journal of Negro Education, 44(3), 353-360.

Hofstede, G. (1996). Cultures and oragnizations, software of the mind: Intercultural cooperation and its importance for survival. New York: McGraw-Hill.

Joy, S., \& Kolb, D. (2009). Are there cultural differences in learning style? International Journal of Intercultrual Relations, 33(1), 69-85.

Kanske, C. (2001). Learning styles of pilots currently qualified in United States Air Force aircraft. Journal of Air Transportation World Wide, 6(2), 33-46.

Kanske, C., \& Brewster, L. (2001). The learning styles of college aviation students. Collegiate Aviation Review, 19(1), 62-70.

Kanske, C., Brewster, L., \& Fanjoy, R. (2003). A longitudinal study of the learning styles of college aviation students. International Journal of Applied Aviation Studies, $3(1), 79-89$.

Kennedy, P. (2002). Learning cultures and learning styles: Myth-understandings about adult (Hong Kong) Chinese learners. International Journal of Lifelong Education, 21(5), 430-445.

Kluckhohn, F., \& Strodbeck, F. L. (1973). Variations in Value Orientations. London: Greenwood Press. 
Kolb, A., \& Kolb, D. (2005). The Kolb Learning Style Inventory-Version 3.12005 Technical Specifications. Boston, MA: Hay Group Transforming Learning.

Lee, K. S., \& Carrasquillo, A. (2006). Korean college students in united states:

Perceptions of professors and students. College Student Journal, 40(2), 442-456.

Loo, R. (1997). Evaluating change and stability in learning style scores: A methodological concern. Educational Psychology, 17(1-2), 95-100.

McCall, L., Klein, B., Piterman, L., \& Lam, T.P. (2005). Learning style preferences for Hong Kong GPs recruited in a distance-learning course. Hong Kong Practitioner, 27(7), 261-267.

Mitsis, A., \& Foley, P. (2004). The effect of students' cultural values on the teacherdriven learning style preference. Proceedings of the 18th Australian and New Zealand Academy of Management Conference (ANZAM). Dunedin: Australian and New Zealand Academy of Management.

Nelson, G. L. (1995). Cultural differences in learning styles. In J. Reid (Ed.), Learning styles in the ESL/EFL classroom (pp. 3-18). Boston, MA: Heinle \& Heinle.

Ramirez III, M. (1989). A bicognitive-multicultural model for a pluralistic education. Early Child Development and Care, 51(1), 129-136.

Romero, J. E., Tepper, B. J., \& Tetrault, L. A. (1992). Development and validation of new scales to measure Kolb's (1985) Learning Style dimensions. Educational and Psychological Measurement, 52(1), 171-180.

Ruble, T. L., \& Stout, D. E. (1992). Changes in learning-style preferences: Comments on Geiger and Pinto. Psychological Reports, 70(3), 697-698.

Singleton, J. (1991). The spirit of gamburu. In B. Finkelstein, A. E. Imamura, \& J. J. Tobin (Ed.), Transcending Stereotypes: Discovering Japanese Culture and Education (pp. 120-125). Yarmouth, ME: Intercultural Press.

Trompenaars, F., \& Hampden-Turner, C. (1997). Riding The Waves of Culture: Understanding Diversity in Global Business (2nd ed.). New York: McGraw-Hill.

Veres III, J. G., Sims, R. R., \& Locklear, T. S. (1991). Improving the reliability of Kolb's revised Learning Style Inventory . Educational and Psychological Measurement, 51(1), 143-150. 


\section{References}

Bartram, D., \& Baxter, P. (1996). Validation of the Cathay Pacific Airways pilot selection program. International Journal of Aviation Psychology, 6(2), 149.

Burke, E., Hobson, C., \& Linsky, C. (1997). Large sample validations of three general predictors of pilot training success. International Journal of Aviation Psychology, $7(3), 225$.

Caterall, J. S., Chapleau, R., \& Iwanaga, J. (1999). Involvement in the arts and human development: General involvement in intensive involvement in music and theatre arts. The Imagination Project at UCLA. University of California at Los Angeles. Retrieved from: http://www.newschool.ie/_fileupload/Image/artsinvolvement.pdf

Caufield, R. (1999). Mozart effect: Sound beginnings? Early Childhood Education Journal, 27(2), 119-121.

Costa-Giomi, E. (1999). The effects of three years of piano instruction on children's cognitive development. Journal of Research in Music Education, 47, 198-212. doi: $10.2307 / 3345779$

Črnčec, R., Wilson, S., \& Prior, M. (2006). The cognitive and academic benefits of music to children: Facts and fiction. Educational Psychology, 26(4), 579-594. doi:10.1080/01443410500342542

Fitzpatrick, K. R. (2006). The effect of instrumental music participation and socioeconomic status on Ohio fourth-, sixth-, and ninth-grade proficiency test performance. Journal of Research in Music Education, 54(1), 73-84.

Hunter, D. R., \& Burke, E. F. (1994). Predicting aircraft pilot- training success: A metaanalysis of published research. International Journal of Aviation Psychology, 4(4), 297.

Hyde, K. L., Lerch, J., Norton, A., Forgeard, M., Winner, E., Evans, A. C., \& Schlaug, G. (2009). Musical training shapes structural brain development. The Journal of Neuroscience, 29(10), 3019-3025. doi:10.1523/JNEUROSCI.5118-08.2009

Johnson, C. M., \& Memmott, J. E. (2006). Examination of relationships between participation in school music programs of differing quality and standardized test results. Journal of Research in Music Education, 54(4), 293-307.

Luuk, K., Luuk, A., \& Aluoja, A. (2009). Predicting professional success of air traffic control personnel from their personality profile at admission to ab initio training. International Journal of Aviation Psychology, 19(3), 235-251. doi:10.1080/10508410902983896 
Moreno, S. (2009). Can music influence language and cognition? Contemporary Music Review, 28(3), 329-345. doi:10.1080/07494460903404410

National Association for Music Education. (2012). Support music: Make your case. Retrieved from www.nafme.org/supportmusic_cases. Reston, VA.

Petress, K. (2005). The importance of music education. Education, 126(1), 112-115.

Rauscher, F. H., Shaw, G. L., Levine, L. J., Wright, E. L., Dennis, W. R., Newcomb, R. L. (1997). Music training causes long-term enhancement of preschool children's spatial-temporal reasoning. Neurological Research, 19, 2-8.

Schellenberg, E. G. (2004). Music lessons enhance IQ. Psychological Science (WileyBlackwell), 15(8), 511-514. doi:10.1111/j.0956-7976.2004.00711.x

Schellenberg, E. G. (2005). Music and cognitive abilities. Current Directions in Psychological Science (Wiley-Blackwell), 14(6), 317-320. doi:10.1111/j.09637214.2005.00389.x 